\title{
A Humanização na Assistência à Saúde Mental no Hospital Geral: UMA Das Alternativas Terapêuticas da Reforma Psiquiátrica Garantida Pelos Direitos Humanos ${ }^{(*)}$
}

\author{
HUMANIZATION IN MENTAL HEALTH ASSISTANCE INSIDE GENERAL \\ HOSPITAL: ONE OF THE THERAPEUTICALALTERNATIVES OF THE \\ PSYCHIATRIC REFORM GUARANTEED BY THE HUMAN RIGHTS
}

Tânia Maria Nava Marchewka ${ }^{(* *)}$

\section{RESUMO}

Este trabalho tem como objeto a assistência à saúde mental nos hospitais gerais como forma de alternativa ao hospital psiquiátrico e à inserção social. Através do levantamento documental, bibliográfico e teórico, e com base na observação da experiência de assistência na unidade psiquiátrica do Hospital São Paulo da Escola de Medicina da Unifesp, buscou-se delinear o paradigma introduzido pela reforma psiquiátrica brasileira e seus desdobramentos nas políticas públicas de saúde mental no Brasil, e traçou-se o desenvolvimento e a aplicabilidade da assistência psiquiátrica no hospital geral, de modo a demonstrar que a efetividade dos direitos humanos depende da humanização do atendimento ao paciente portador de transtorno mental.

\section{Palavras-chave}

Direitos Humanos; Direito Sanitário; Hospitais Gerais; Reforma Sanitária; Saúde Mental.

(*) Extraido de Monografia apresentada no Curso de Especialização em Saúde Mental e Qualidade de Vida no Hospital Geral, no ano de 2005, na Universidade Federal de São Paulo - UNIFESP.

(**) Procuradora de Justiça do Ministério Público do Distrito Federal e Territórios (MPDFT), Doutora em Direito, Justiça e Sociedade, Mestre em Direito Penal (Universidade Gama Filho/RJ), especialização em Gestão de Serviços de Saúde Mental - UNB, Especialização em Direito Sanitário - UNB, Especialização em Saúde Mental e Qualidade de Vida no Hospital Geral UNIFESP. Professora de Direito Penal da Universidade Gama Filho/RJ e Direito Penal do Uniceub. Professora de Direito Penal e Criminologia e Coordenadora do Curso de Direito do Instituto Superior Cenecista - Unai - MG. Diretora Financeira e Coordenadora em Brasilia da Associação Brasileira dos Professores em Ciências Penais. E-mail: <taniamm@mpdft.gov.br>. 


\section{ABSTRACT}

This work is focused in the mental health assistance in general hospitals as an alternative for the psychiatric hospital and social insertion. Through the documentary, bibliographical and theoretical survey and based on the observation of the experience of assistance in the psychiatric unit of the São Paulo Hospital - School of Medicine/Unifesp - it has been searched to delineate the paradigm introduced for the Brazilian psychiatric reform and its unfoldings in the public politics of mental health area in Brazil. It has been also described the development and the applicability of the psychiatric assistance in general hospitals, in order to demonstrate that the effectiveness of the human rights depends on the humanization of the attendance to the patient.

\section{Key words}

General Hospitals; Human Rights; Mental Health; Sanitary Law; Sanitary Reform.

\section{I - INTRODUÇÃO}

O tema da saúde mental desperta muito interesse para historiadores, filósofos, médicos, psiquiatras, psicólogos, psicanalistas, parlamentares, sociólogos, cientistas, cineastas, profissionais da saúde, do direito e outros. Um enfoque bastante interessante é o da saúde mental envolvendo os direitos humanos e direitos fundamentais. Este trabalho aborda essa relação. Porém, levantar questões atreladas ao tema e aos direitos humanos não é tarefa fácil. Se por um lado, lidar com o transtorno mental no hospital geral exige delicadeza, amor e paciência, por outro, investigar a assistência nos hospitais gerais remete à origem, ou seja, à necessidade de atentar para o nascimento das unidades psiquiátricas no momento em que essa assistência começou.

Dessa maneira, este trabalho de investigação nasceu da necessidade de refletir sobre o conjunto de experiências que se desenvolveram em torno dos novos paradigmas na assistência psiquiátrica, com atenção aos serviços alternativos ao hospital psiquiátrico.

A ênfase da pesquisa buscou articular o objeto de estudo com a teoria da estigmatização, na qual o hospital psiquiátrico é tido como local de etiquetamento e exclusão social: aquilo que não funciona satisfatoriamente produz sofrimento e registra uma "marca". Fica evidente que, ao enfocar a assistência ao portador de transtorno psíquico, optou-se pelo paradigma teórico da estigmatização, afastando o enfoque clínico que se ocupa em 
descrever as patologias e fatores causais do transtorno psíquico. Contudo, o mais importante é revelar como se garante os direitos humanos no contexto do Estado Democrático de Direito.

Este trabalho tem como objeto a assistência à saúde mental nos hospitais gerais como forma de alternativa ao hospital psiquiátrico e à inserção social. Para tornar possivel a investigação dentro de um território limitado, optou-se por observar a experiência da assistência na unidade psiquiátrica do Hospital São Paulo da Escola de Medicina da Unifesp, o que possibilitou o desenvolvimento de uma análise mais ampla sobre o tema proposto. Porém, vale ressaltar que apenas a leitura desse recorte obviamente não esgotou o assunto.

O processo de investigação implicou também em um levantamento documental, bibliográfico, de histórias e movimentos sociais. Estes elementos gradativamente formaram uma certa unidade, por meio de sua organização e articulação, levando à composição de relações sociais e conexões que, por sua vez, enredaram políticas públicas de saúde mental.

A reforma psiquiátrica compõe esse processo e, aos olhos do investigador, dela foram selecionados os mais significativos pedaços, fragmentos, detalhes e indícios da proteção dos direitos do portador de transtorno mental, bem como aqueles elementos mais qualificados para caracterizar a experimentação na relação Psiquiatria/Justiça. Buscou-se encontrar os velhos e os novos sentidos, caracterizando a análise como baseada na trajetória de elaboração do pensamento, e de construção e revelação de um modo singular de apreender a assistência à saúde mental dentro de um novo paradigma, ou seja, de uma outra forma de compreender os fenômenos explorados.

Assim, o objetivo geral é o de buscar uma maior compreensão sobre a construção dos novos modelos na assistência à saúde mental e de seus desdobramentos em direção à humanização do atendimento ao portador de transtorno mental, com vistas à formulação de uma proposta alternativa ao hospital psiquiátrico.

O presente trabalho não alcança as políticas públicas de saúde de um modo geral, isto é, a totalidade da reforma sanitária inserida com a Lei $n$. $8.080 / 90$, nem pretende pôr a descoberto a fenomenologia das patologias dos portadores de transtornos mentais. Procura revelar os novos modelos na assistência à saúde mental como direito que garante a cidadania e a dignidade do portador de transtorno mental, a partir de sua inserção social.

Assim, o objetivo específico da investigação constitui no levantamento bibliográfico e documental referente à assistência psiquiátrica e à mudança de paradigma na lida com a saúde mental, com enfoque para a garantia dos direitos humanos.

A delimitação do tema, do objetivo geral e específico, imprescindiveis a qualquer trabalho científico, não menosprezou o papel do Judiciário e do 
Ministério Público na proteção dos direitos fundamentais. O estudo particularizou a assistência psiquiátrica nas unidades psiquiátricas dos hospitais gerais, visando a compreensão da reorientação da assistência dos portadores de sofrimento psíquico.

De qualquer forma, na revisão bibliográfica identificaram-se algumas questões complementares como: a existência da teoria da reação social a partir de autores como Lola Aniyar de Castro (1983); Carlos Roberto Bacila (2005) para a investigação comparada sobre os estudos de Foucault (1999); a questão do etiquetamento do portador de transtorno mental, abordada por Goffman $(1974 ; 1975)$ e Basaglia $(1968 ; 1985)$; e tentou-se articular o processo histórico e social que deu origem à prática psiquiátrica no hospital geral com Botega e Dalgalarrondo (1977), apresentando também o painel da reforma psiquiátrica no contexto do Estado Democrático de Direito.

O eventual mérito da pesquisa, e sua característica inovadora, reside, justamente, na assistência psiquiátrica do hospital geral, como assistência à saúde mental preconizada no paradigma introduzido pela reforma psiquiátrica brasileira como garantia dos direitos humanos.

\section{II - PRINCIPAIS ASPECTOS DA TRAJETÓRIA DA PSIQUIATRIA E OS NOVOS PARADIGMAS DA REFORMA}

Michel Foucault, em História da Loucura na Idade Clássica, ao fazer uma breve construção sobre a história da loucura desde a época do Renascimento até o século XIX, analisa a mudança na representação do conceito de loucura, que inicialmente é compreendida como uma experiência cósmica e trágica, transformando-se em uma reflexão puramente crítica e racional. Essa última representação refletirá na organização social, pois a internação torna-se uma forma do Estado isolar o que reconhece como marginal, insensato e obstáculo da ordem, para salvaguardar "a razão e a moralidade".

No fim do século XVIII ocorre uma outra transformação quando se produz a "patologização" da loucura, que passa a ser reconhecida como doença mental, e o médico, por sua vez, passa a ingressar no asilo com função terapêutica.

Foucault aponta que foi através da noção de monomania que a loucura passou a ser vista como uma doença que não se caracterizava necessariamente pelo delírio e, poderia, portanto, passar-se despercebida; o autor mostra que foi através desta noção que a loucura apareceu, no século $X X$, como algo invisível, imprevisível e perigoso.

Nessa época, a psiquiatria estava conseguindo ocupar um lugar no campo jurídico-penal e a questão da monomania homicida tornou-se foco 
do conflito de competências, uma vez que os juristas criticavam tal diagnóstico, considerando-o um álibi fácil aos criminosos.

As circunstâncias que levaram a sociedade européia do século XVIII a considerar a loucura e a pessoa do louco um problema social levaram também à criação de instituições para controlá-los e, eventualmente, tratá-los. No Brasil dos primeiros anos do século XIX, ante as peculiaridades da vida econômica e social desde a época colonial, houve algumas diferenças quanto às causas que levaram àquelas circunstâncias.

O manicômio, pela agudeza de suas contradições, é laboratório para compreensão das instituições totais. Erving Goffman, em seu conhecido livro Manicômio, Prisões e Conventos $(1974 ; 1975)$, evidencia que a natureza total e totalizadora, assim como a interdição com o mundo externo, são as características fundamentais das instituições fechadas. As descrições minuciosas presentes em suas análises explicitam a analogia de funcionamento entre essas organizações, assinalando que o "produto de seus internos" é, sobretudo, fruto da vida institucional e não do processo singular da doença.

Os autores italianos, ao analisarem o manicômio, superam o eixo da literatura de Goffman sobre as instituições totais. Para Franco Basaglia, por exemplo, o fundamental é colocar em discussão a função social das instituições, revelar (1) "a funcionalidade da instituição em relação ao nosso sistema social que sobrevive excluindo (e, portanto, oprimindo, mortificando e destruindo) os elementos de distúrbio".

No mesmo sentido, a criminóloga venezuelana Lola Aniyar de Castro (1983), ao apontar a psiquiatria tradicional, o manicômio e o cárcere como formas de violência institucional, fundamenta sua posição com Basaglia, para o qual a psiquiatria tradicional cria uma distância entre paciente e médico, instaurando uma relação que denominou de "objetal", impeditiva do doente mental sair de um círculo "coisificante". Aniyar de Castro afirma a existência de uma relação de poder institucional, terapêutico e carismático, que impede o estabelecimento de uma relação autêntica entre ambos.

O psiquiatra italiano Franco Basaglia (1924-1980) foi a principal figura da chamada luta antimanicomial na década de 60. Liderou a experiência de abertura e posterior extinção de dois manicômios, na cidade de Trieste e Gorizia, na Itália. As experiências foram bem-sucedidas. Desde então, Trieste se tornou referência mundial na democratização do atendimento psiquiátrico(2).

(1) BASAGLIA, F. A Instituição negada. Rio de Janeiro: Graal, 1985. p. 273-274.

(2) Basaglia (1972) propõe animar a comunidade terapêutica nos hospitais onde ocorra os seguintes processos: 1) liberdade de comunicação entre pacientes, médicos, enfermeiros e empregados (sem hierarquia); 2) análise do que acontece na comunidade em termos de dinâmica e interpessoal; 3) tendência à destruição da autoridade hierárquica, em contraste com o hospital tradicional no qual o paciente está no mais baixo escalão e todo o hospital descarrega as suas tensões contra ele; 4) possibilidades de desfrutar de ocasiões de reconhecimento social (bailes, saidas, teatros, projeções etc.); 5) uma reunião pessoal médico-paciente, freqüentemente diária e outra mais restrita. 
Nas últimas décadas muitos países vêm implementando a Reforma Psiquiátrica, tais como: Psiquiatria Democrática (Itália), Comunidade Terapêutica (Inglaterra), Psiquiatria de Setor (França) e Psiquiatria Comunitária (USA).

No Brasil, o modelo psiquiátrico hospitalar foi considerado ultrapassado pelo Conselho Nacional de Saúde, ligado ao Ministério da Saúde, a partir de 1992. Em 1994, foi criada a Comissão Nacional de Reforma Psiquiátrica, que tentou implantar um modelo de tratamento centrado na assistência diversificada - apoio psicológico, reintegração social, tratamento em regime aberto etc. - e não mais na internação.

Esse novo enfoque da psiquiatria possibilita uma nova rede, novas alianças sociais e projetos coletivos de vida, que ultrapassam as referências à pura mercadoria do dinheiro e valorizam a comunicação direta entre as pessoas como uma prática essencial.

O primeiro provimento normativo brasileiro que tratou da doença mental foi o Decreto n. 1.132/1903, o qual dispunha sobre a reorganização à assistência aos alienados. O decreto objetivava unificar no Brasil a política assistencial e estimular a construção de hospitais especializados nos Estados-membros. O modelo assistencial proposto, que vigorou até a edição da Lei n. 10.216/2001, era o hospitalocêntrico e centralizado a vedação de colocação de alienados em prisões, que releva o tratamento médico. Assim, a assistência ao doente mental, nos últimos três séculos limitou-se, com raras exceções, à reclusão em instituições fechadas e desumanizadas. Levou à restrição do indivíduo e seu distanciamento do convivio familiar e social, tendo como conseqüência direta a cronificação, resultando em perda do vínculo afetivo, social e capacidade produtiva.

\section{III - POLÍTICAS PÚBLICAS DE SAÚdE MENTAL NO BRASIL}

Ao longo da última década, uma série de fatores sociais, econômicos e políticos determinou modificações no cenário internacional e nos contextos nacionais, na área da saúde mental envolvendo o Direito. Como qualquer área da atividade política, econômica, social e jurídica, os direitos e os serviços de saúde mental estão expostos a transformações.

Em 1987, iniciou-se o trabalho de transformação do hospital psiquiátrico. Trabalhadores em saúde mental agruparam-se em torno da utopia Por uma sociedade sem manicômio. Diferentemente do movimento reformista, a nova proposição não se apresentava como solução, mas apontava uma reviravolta do pensar na questão da loucura, esboçando uma crítica ao paradigma psiquiátrico. O manicômio é compreendido como síntese e metáfora da instituição da violência, e o movimento afirmou a necessidade de enfrentá-lo prioritariamente. 
Como se vê, a reforma psiquiátrica brasileira se iniciou na década de 70 , baseada no modelo italiano. Essa reforma provocou fundamentalmente uma nova concepção dos transtornos mentais, estimulando o respeito às diferenças e a elaboração do conceito de cidadania.

O final da década de 80 em nosso país foi excepcionalmente produtivo em vários setores e nos deixou importantes referenciais de transformação no interior da sociedade. A Constituição Federal de 1988 (e seus desdobramentos) no campo da saúde criou o Sistema Único de Saúde - SUS (Lei n. 8.080/90). Contudo, as políticas de saúde no Brasil no periodo de 19801990 tiveram o seu desenvolvimento contextualizado em uma profunda crise econômica que, apesar de coincidir com o processo de redemocratização do país, não garantiram à sociedade o direito à cidadania. Nesse cenário foram gerados os princípios da Reforma Psiquiátrica Brasileira, tendo alguns marcos de grande relevância política, como as Conferências Nacionais de Saúde e em saúde mental, as intervenções em órgãos públicos e privados, os movimentos sociais de profissionais de saúde mental, bem como os dos usuários e familiares dos serviços de saúde mental.

O Projeto de Lei n. 3.657/1989 de autoria do Deputado Paulo Delgado propunha a extinção progressiva dos hospitais psiquiátricos e sua substituição por outras formas de assistência que não representassem o afastamento absoluto do indivíduo de seu meio social. Tramitou quase 12 anos, enfrentando uma forte oposição, tanto de empresários da psiquiatria, quanto dos representantes da psiquiatria tradicional e do Poder Legislativo.

Em 2001, por ocasião do Dia Mundial da Saúde - data comemorada pela Organização Mundial de Saúde (OMS) que naquele ano foi dedicada ao tema saúde mental com o lema "Cuidar sim, excluir não" - o Ministério da Saúde investiu fortemente na aprovação deste Projeto de Lei. Em 21 de março de 2001, a Câmara dos Deputados aprovou o substitutivo ao PL, de autoria do Senador Sebastião Rocha. Sancionado pelo Presidente da República no dia 6 de abril de 2001, véspera do Dia Mundial da Saúde, tornou-se a Lei n. 10.216/2001, que dispõe sobre a proteção e os direitos das pessoas portadoras de transtornos mentais e redireciona o modelo assistencial em saúde mental. A referida lei determinou a aplicação de uma política nacional específica para a proteção dos direitos do portador de transtorno mental como efetivação da opção pela desinstitucionalização no âmbito do Sistema Único de Saúde.

A Lei n. 10.216/2001 define a proteção dos direitos dos portadores de transtornos mentais, estabelecendo os objetivos do tratamento em regime de internação, e regulamenta as internações involuntárias e compulsórias. Além disso, determina que o tratamento dispensado seja integral e oferecido por equipe multidisciplinar, bem como que a internação hospitalar só deve ser utilizada em última instância, quando os recursos extra-hospitalares e 
ambulatoriais não forem suficientes. Estabelece também a descentralização do modelo assistencial, baseando-se nos princípios de utilização de rede diversificada de serviços, comunitária, na qual a atuação terapêutica seja a menos restritiva possível, ou seja, aquela em que o paciente não sofra qualquer tipo de marginalização. Outra inovação é a proibição de internação em instituição asilar que não contemple as características adequadas e necessárias ao tratamento do paciente.

Portanto, mais do que uma norma jurídica, a Lei n. 10.216/2001 é também uma carta de princípios, estabelecendo os direitos dos portadores de transtornos mentais, desestigmatizando-os, garantindo o acesso aos melhores recursos terapêuticos disponíveis e fomentando a criação de rede de serviços, diversificada e descentralizada, através de políticas públicas específicas de desinstitucionalização e de tratamento ambulatorial e comunitário.

\section{IV - A ASSISTÊNCIA PSIQUIÁTRICA NO HOSPITAL GERAL}

A mudança do atendimento psiquiátrico hospitalar para a assistência comunitária tem sido a grande meta das equipes de saúde mental de vários países, assim como no Brasil, apesar das resistências. Pressupõe a transferência do eixo hospitalar para atendimento nos serviços diretamente vinculados à comunidade, aproveitando toda a rede de assistência pública e do setor privado, uma vez que todos prestam serviços de relevância pública. Esse novo modelo foi desenhado a partir da Declaração de Caracas $^{(3)}$ e de vários eventos nacionais e internacionais.

Por outro lado, um conjunto de portarias ministeriais estabeleceu administrativamente as bases dessas mudanças, por exemplo, as Portarias ns. $6.281 / 2000$ e 2.391/2002. A atual Portaria n. 2.391/2002 regulamenta o controle das internações psiquiátricas involuntárias de acordo com o disposto na Lei n. 10.216/2001. Aqui é importante destacar a participação do Ministério Público na fiscalização das internações psiquiátricas. A Lei n. 10.216/ 2001 inseriu no art. $8^{\circ}, \S 2^{\circ}$ essa atribuição para o Ministério Público. Percebese, portanto, nesse processo modernizador e democrático, o envolvimento das práticas do Ministério Público no âmbito político-jurídico, político-institucional e político-organizacional. Esse processo deve ser entendido como implementação do direito universal e fundamental a ser executado pelo Sistema Único de Saúde, que objetiva eficiência, eficácia e eqüidade.

(3) Vale ressaltar a Carta de Brasilia 2005 - Principios Orientadores para o Desenvolvimento da Atenção em Saúde Mental nas Américas, publicada pelo Ministério da Saúde do Brasil, a Organização Panamericana da Saúde e a Organização Mundial da Saúde, que convocou a "Conferência Regional para a Reforma dos Serviços de Saúde Mental: 15 Anos depois da Declaração de Caracas", nos dias 7 ao 9 do mês de novembro do ano de 2005, com o objetivo de avaliar os resultados obtidos desde 1990. 
Observamos na pesquisa, inicialmente, que as unidades psiquiátricas em hospital geral, como o hospital destinado a atender pacientes com transtornos mentais, tiveram sua ação limitada às determinadas camadas da população (hospital militar, hospital previdenciário) ou com finalidade específica (hospital de ensino)(4). Constatou-se a exigência de um hospital geral novo, posto que foi constituída uma unidade específica nesta instituição para desinstitucionalização dos portadores de transtornos mentais. Eis aí a necessidade fundamental de uma maior integração, inclusive com os demais serviços, tanto com os da própria instituição, como com os vinculados à comunidade. Isto exige, pois, mudança de mentalidade.

Aqui, procurou-se buscar novas posturas profissionais e gerenciais em nome das mudanças funcionais do hospital geral, em face das novas tarefas na reorientação da assistência psiquiátrica, em promoção dos direitos do portador de transtorno mental. Dessa forma, buscou-se neste trabalho conhecer a unidade psiquiátrica do Hospital São Paulo em particular, por tratar-se de uma unidade que tem avançado em termos mais próximos da reforma psiquiátrica. Seria um modelo possível de ser adequado à política pública de saúde mental, pois, propício para uma intervenção interdisciplinar em saúde mental.

Ademais, as diretrizes ali encontradas, além de apontarem para a assistência integrada com os Centros de Atenção Psicossocial (CAPS) e os Núcleos de Atenção Psicossocial e Residências Terapêuticas (NAPS), indicam a formação dos profissionais em saúde mental. Nesse sentido, percebeu-se que a equipe já se encontra sensibilizada, pronta a participar do processo de desinstitucionalização do portador de transtorno mental, não mais como tuteladora do indivíduo, mas sim, como instituição de resgate dos direitos humanos.

\section{V - DESENVOLVIMENTO DA IMPLANTAÇÃO DA ASSISTÊNCIA PSIQUIÁTRICA NO HOSPITAL GERAL}

Entre as principais razões da implementação das Unidades Psiquiátricas no Hospital Geral, Botega e Dalgalarrondo (1977) pontuam as seguintes observações:

- o Estado passou a ter um papel fundamental na regulação social, incluindo-se as áreas de assistência e proteção dos doentes;

(4) Outros autores enfocam este aspecto: SZWARC, Wilma Szarf. A Unidade Psiquiátrica do Hospital São Paulo: relato de uma experiência. 1995. Dissertação (Mestrado) - Universidade Federal de São Paulo - Escola Paulista de Medicina, 1995; BRASIL, M.A. A unidade psiquiátrica em hospital geral. 1982. Dissertação (Mestrado) - Instituto de Psiquiatria da Universidade Federal do Rio de Janeiro, Rio de Janeiro, 1982. 
- experiências de pequenas enfermarias psiquiátricas em hospitais militares gerais mostraram concretamente aos médicos, ao pessoal técnico e aos administradores, a possibilidade de se tratar eficazmente doentes mentais em hospitais gerais;

- crítica aos hospitais psiquiátricos: a) denúncias de sua dimensão segregadora, estigmatizante e produtora de anomia; b) Fantasmas dos campos de concentração da II Guerra Mundial; c) condenação de macroinstituição para desadaptados sociais; d) internação psiquiátrica não deveria mais ser vista como "centro da assistência psiquiátrica";

- a assistência psiquiátrica como integrada a estruturas assistenciais extramuros (ambulatórios e centros de saúde regionalizados);

- busca da continuidade terapêutica;

- desenvolvimento de abordagens terapêuticas que viabilizam e agilizam o tratamento de quadros psiquiátricos graves (convulsoterapia décadas de 40 e 50) e a psicofarmacoterapia (década de 50);

- desenvolvimento de abordagens psicoterapêuticas (uso de psicanálise em instituições, técnicas grupais, psicoterapia breve etc.) e socioterapêuticas (terapia ocupacional, baboterapia, comunidade terapêutica, lilieu etc.);

- reconhecimento crescente da importância do ensino de Psiquiatria no curso de graduação médica, ressaltando a importância da Unidade Psiquiátrica no Hospital Geral em hospitais de ensino.

A proposta de unidades psiquiátricas no hospital geral, segundo Botega e Dalgalarrondo, surgiu da crítica ao hospital psiquiátrico tradicional, após as denúncias de Foucault, como uma das alternativas terapêuticas no século $X X$. O início das unidades psiquiátricas no hospital geral, em seu sentido moderno, ocorreu em 1902 - com planejamento terapêutico, integração à medicina geral, internações breves com rápido retorno à comunidade e serviços de interconsulta e emergência - no Albany Medical Center, em Nova lorque. A partir daí foram surgindo experiências muito esparsamente ao longo das décadas de 20 e 30, segundo estudos de Detre e Kutter datados de 1975.

No contexto histórico da psiquiatria no Hospital Geral, José Cassio do Nascimento Pitta (2005) descreve a organização dos serviços, com base no modelo de atendimento oriundo dos hospitais ingleses e pontua as vantagens e desvantagens desse modelo. Afirma que, somente após a Segunda Grande Guerra Mundial, com a experiência de pequenas enfermarias psiquiátricas em hospitais militares gerais, surgiram as criticas ao estigma e a segregação que os hospitais psiquiátricos propiciavam aos indivíduos internados. Fundamenta seu trabalho a partir do enfoque adotado nos estudos de Botega e Dalgalarrondo (1977). No Brasil, Pitta descreve como se deu a implantação das primeiras unidades psiquiátricas no hospital geral, criadas 
em 1954, tendo como referência o Hospital das Clínicas da Universidade Federal da Bahia e o Hospital dos Comerciários de São Paulo. Expõe no contexto histórico da assistência psiquiátrica até chegar-se a uma contribuição do modelo da estrutura do Hospital São Paulo da Escola Paulista de Medicina. Descrevendo a organização da assistência, utiliza como referência $o$ atendimento com práticas terapêuticas que evitam as condições facilitadoras da evolução crônica da doença mental.

Com base nestes autores é possivel afirmar que as inovações nesse campo trazem também novas exigências para o profissional, traduzidas como conhecimento de diferentes aspectos envolvidos no cuidado dos clientes/ usuários e na organização dos serviços de saúde mental. Ou seja, tornaramse indispensáveis a formação com forte recorte no campo da saúde pública/ saúde coletiva e a capacidade de refletir sobre as relações saúde/sociedade, individuo/Estado e instituições do campo. É necessário, pois, a formação dos profissionais no campo da saúde mental para que possam aplicar e desenvolver conceitos necessários à boa prática de operação e gestão dos serviços, assim como na formulação de políticas públicas na área.

Portanto, capacitar a rede básica de saúde para "um olhar em saúde mental", conforme o enfoque referido acima, é um passo fundamental para a melhoria da saúde das comunidades. Ademais, o vínculo com os profissionais tende a ser mais próximo. A equipe pode efetivamente contribuir na resolução da desconstrução do hospital psiquiátrico, além de promover simultaneamente o cuidado com o "cuidador", que são os familiares ou pessoas próximas ao usuário. Eles necessitam de atenção a sua própria saúde mental. Um esclarecimento, um suporte individual aos membros da família ou mesmo uma reunião de familiares pode representar um salto qualitativo na evolução dos usuários da saúde mental e na efetivação da reforma psiquiátrica.

A efetivação da assistência à saúde mental depende do trabalho das equipes dos profissionais da área que atuam na rede básica de saúde, em especial dos hospitais gerais que trabalham sob a estratégia da saúde em geral. São urgentes e necessárias, portanto, a assistência à saúde mental no hospital geral e a possibilidade de trabalho conjunto com os serviços substitutivos extra-hospitalares (NAPS, CAPS e Residências Terapêuticas).

Garantir os direitos dos usuários no hospital geral exige um atendimento integrado que possa oferecer um contraponto ao processo de fragmentação rígida dos cuidados, característico dos hospitais gerais em função da alta rotatividade de cuidados. A política de saúde no atendimento integrado tem como objetivo envolver um plano de ação que seja capaz de atingir a instituição de forma plena, abrindo caminho para uma mudança de concepção e mentalidade. Para tanto, um aspecto importante deve ser ressaltado: um cuidado especial é dedicado ao processo de reinserção social e reabilitação, na forma de acompanhamento, encaminhamento e atenção à família e à rede de apoio social. 


\section{VI - APLICABILIDADE DA ASSISTÊNCIA PSIQUIÁTRICA NO HOSPITAL GERAL}

O redirecionamento da assistência psiquiátrica como garantia de cidadania do portador de transtorno psíquico, baseado nos conhecimentos teóricos e práticos das unidades psiquiátricas, ainda não atingiu a abrangência adequada à psiquiatria contemporânea, com as políticas públicas do Sistema Único de Saúde, para iniciar os referenciais e defender o respeito à dignidade humana.

O Governo e a Secretaria de Saúde do Distrito Federal fazendo cumprir recomendações nacionais e internacionais, amparados no art. 211 da sua Lei Orgânica, Lei n. 975/95-GDF, elaboraram o Plano Diretor de saúde mental da FHDF, Relatório Final do I Fórum de Saúde Mental do DF e da III Conferência de Saúde do DF, para implementação e reordenamento da atenção à saúde mental (Reforma Psiquiátrica) no DF.

Este documento apresenta a proposta de criação e implementação dos Serviços de Saúde Mental dos Hospitais Gerais. Segundo este plano, os serviços são estruturados por Emergências Psiquiátricas, ininterruptamente, Enfermarias, para observação e internação breve, Interconsultas, para o acompanhamento de pacientes internados nas diversas Clínicas do Hospital, Interconsulta Ambulatorial, referência para outras especialidades.

No referido Plano Diretor os serviços de saúde mental do Hospital Geral estão interligados entre si e com os demais serviços da rede de saúde mental (equipes multidisciplinares de saúde mental em hospitais gerais, CAPS, NAPS e Centros de Convivência), centros de saúde, além dos serviços contratados do SUS.

$\mathrm{Na}$ verdade, o novo modelo assistencial proposto pelo SUS baseia-se numa concepção atualizada do processo saúde-doença e numa visão de intervenção nesse processo, ou seja, num novo modelo de prática sanitária. No primeiro caso, evoluindo de uma concepção negativa de saúde, como a ausência de doença, para uma concepção afirmativa, como qualidade de vida. No segundo caso, evoluindo das práticas centradas na assistência médica individual para as práticas capazes de intervir no processo por meio de ações integradas de saúde.

Ademais, para a organização de modelos de atenção à saúde mental no hospital geral capazes de responder a essa complexidade, é necessária a articulação entre três esferas de governo na estruturação e implementação de uma rede de serviços em saúde mental que inclua a promoção e a proteção dos direitos do portador de transtorno mental e da saúde, as atividades de controle de risco e de regulação, bem como controle do monitoramento das práticas, resultando em indicadores que traduzam a realidade da saúde mental nos hospitais gerais no país. 


\section{VII - HUMANIZAÇÃO NOS HOSPITAIS GERAIS: EFETIVIDADE DOS DIREITOS HUMANOS}

Como foi possivel perceber, ao longo das últimas décadas, a partir de debates e resoluções, a assistência ao paciente portador de transtorno mental tem passado por transformações estruturais. Com as discussões conceituais colocadas, verifica-se que a saúde mental deve ser tratada como a vinculação dos direitos humanos com os fundamentais, recebendo a chancela da comunidade internacional, que mantém um processo histórico de conquistas e reivindicações, tanto nas esferas sociais como nas econômicas. A convergência da saúde mental com os princípios que intitulam os direitos fundamentais é evidente, sendo indispensável à dignidade do homem.

Portanto, a assistência à saúde mental é um dos direitos fundamentais do homem. As intervenções baseadas nas experiências anteriores, assim como postulações teóricas e legitimadas por um modelo científico atual, permitem realizar uma ação de forma estruturada e vinculada às reais necessidades de uma comunidade que contém indivíduos socialmente desvalorizados.

As equipes especificas de saúde mental e as inseridas também na rede básica de saúde, principalmente as que trabalham na área judiciária, devem questionar e refletir sobre os códigos Civil e Penal, assim como seus procedimentos processuais e institucionais, no que concerne aos institutos que tratam da incapacidade civil, imputabilidade e periculosidade. Algumas das funções dessas equipes seriam colaborar com o Ministério Público e garantir os direitos consagrados na Magna Carta, o que merecerá enorme relevância para o campo da saúde mental, conforme dispõe o art. 129, inciso II, da Constituição Federal e a Lei n. 10.216/2001.

A proteção dos direitos dos assim chamados "portadores de transtornos mentais", através da legislação vigente, deve ser compreendida como uma etapa inicial do processo da inclusão efetiva desses indivíduos na sociedade brasileira. Essa conquista pode estimular as soluções que promovam a real integração dessas pessoas. Isto significa organizar, planejar e financiar atividades em todos os níveis, bem como dotar as políticas públicas com o caráter da interdisciplinaridade.

Uma política social, com a presença de todos os segmentos da população, deve envolver os instrumentos legais e normativos, garantindo o direito à acessibilidade. Os recursos da comunidade e serviços urbanos próximos devem ser integrados, facilitando a vida cotidiana. As barreiras sociais podem ser minimizadas através de campanhas de sensibilização e educação pública, no intuito de modificar as atitudes e o comportamento em relação às pessoas com transtorno mental. As estratégias para a promoção destes direitos devem seguir a hipótese de que enfrentar as dificuldades relacionadas à exclusão depende de soluções para defender os direitos 
humanos. Projetos na área social e intervenção do poder público são essenciais para resolver os problemas que forem surgindo ao longo de processo de inserção social do portador de transtorno mental.

A criação de novas modalidades assistenciais, dispositivos e ações, devem ser desenvolvidas a partir de múltiplos projetos relacionados à humanização e qualidade de vida no hospital geral. Cabe ressaltar, como proposta de ação, alguns aspectos que merecem atenção no processo de implementação das unidades psiquiátricas nos hospitais gerais, bem como suas metas e estratégias de atuação, listadas a seguir:

- processos de vistoria, fiscalização, supervisão e recredenciamento dos hospitais gerais;

- criação de várias associações de usuários, familiares e profissionais, proporcionando novas formas de participação e inserção social;

- aprovação de leis estaduais e municipais orientadas pelas diretrizes da Lei n. 8.080/90 (SUS);

- equipe multiprofissional e de intervenção interdisciplinar;

- controle social;

- eqüidade;

- grupo de trabalho integrado;

- preservação e conservação do ambiente;

- promoção e defesa da saúde;

- publicidade.

\section{Metas}

- envolvimento de todo o conjunto de serviços e profissionais da Unidade de Saúde ou Hospitalar com trabalho em saúde mental e Qualidade de Vida através de reuniões clínicas, eventos técnicocientíficos, projetos de desenvolvimento pessoal, entretenimento, atividades culturais e educativas, acompanhamento conjunto de pacientes etc.;

- planejamento anual, monitoramento e avaliação anual;

- atuação interdisciplinar de profissionais de outros setores do hospital;

- avaliação trimestral de usuários através de indicadores, considerando também o grau de envolvimento dos familiares e indicadores de relevância como inserção social;

- realização de trabalho com equipe multidisciplinar com funcionamento interdisciplinar. 


\section{Estratégias}

- necessidade de superação de modelo assistencial centrado na referência da internação hospitalar;

- formalização de esboço de um novo modelo assistencial fundamentado nos conceitos de atenção integral, direitos humanos e cidadania;

- trabalhar com o conceito de saúde como direito de cidadania e fruto da qualidade de vida;

- estimular a extensão da cobertura e melhoria da qualidade de vida do atendimento no sistema de saúde;

- desenvolver um processo de formação permanente com todos os profissionais;

- informar a população a respeito dos serviços e dos fatores determinantes das doenças;

- incentivar a organização da comunidade para exercício de seus direitos sociais;

- realizações de pesquisas sobre o funcionamento dos hospitais gerais, produção e atualização de dados sobre a assistência à saúde mental e qualidade de vida;

— inclusão de ações de saúde mental e qualidade de vida no Programa Saúde da Familia;

— incentivo à implementação de novos serviços extra-hospitalares por meio de encaminhamento de proposta de convênio.

\section{VIII - CONCLUSÃO}

No presente trabalho procurou-se contextualizar e sistematizar os padrões políticos, culturais e econômicos na lida com o doente mental. Tratou-se também dos processos de redemocratização das políticas públicas de saúde, especialmente da saúde mental nos últimos decênios, com a reforma psiquiátrica.

Pois bem, há mais de dez anos o Brasil possui uma Constituição, na qual, dentre as suas várias dimensões, destaca-se a de sua instrumentalização em prol da universalização da cidadania. A carta consiste num complexo de instituições que propiciam novos espaços à publicização de conflitos sociais, mediante uma redefinição entre o Estado e sociedade. Os regimes democráticos contemporâneos são capazes de possibilitar as demandas provenientes da sociedade civil, fortalecê-la, como ainda, solidarizar-se com a mesma para a realização do interesse público. Assim, possibilita a efetivação de diversos direitos de cidadania: civis, políticos, sociais etc. 
Como se vê, na contextualização da reforma sanitária e psiquiátrica, a sociedade civil inevitavelmente emergiu em confronto com a institucionalidade autoritária que the era desfavorável. As organizações sociais com interesse pela saúde passaram a exigir melhores condições para a preservação da mesma, como também da saúde mental e da plena dignidade para os portadores de transtornos psíquicos. A transição à democracia, enquanto processo de reinstitucionalização, implicou na liberação e incorporações graduais de arenas públicas e de atores sociais e políticos. $\mathrm{Na}$ medida em que a orientação dos movimentos sociais de influir ou até de capturar agências estatais encontrava-se na esfera pública, que se tornava menos opressiva e mais inclusiva, conseguiu-se como resultado uma construção onde o Estado e a sociedade civil se imbricam.

Ademais, os princípios da atenção à saúde ressaltam os direitos humanos, assim como o Sistema Único de Saúde, além da universalidade do acesso às ações e aos serviços, e postulam a assistência como igualitária e integral independente de cor, raça, condição social, vinculação partidária, além de objetivarem a preservação de autonomia do usuário, do direito do indivíduo à informação sobre sua saúde. Esses principios visam à descentralização, regionalização e hierarquização da rede de serviços de saúde, à humanização do atendimento, ao acesso às ações e recursos intersetoriais; e a participação da comunidade deve orientar as políticas de saúde e a otimização dos modelos assistenciais.

Com essa abertura política e conseqüente redemocratização dos hospitais psiquiátricos nos últimos anos, acredita-se e se espera que as unidades psiquiátricas dos hospitais gerais integrem as propostas da reforma psiquiátrica, com novas alternativas para as necessárias internações de curta duração e, com isso, reorientem a assistência à saúde mental dentro deste novo paradigma de atendimento integrado com os demais serviços substitutivos em saúde mental.

Assim, no momento em que surgirem estas novas práticas, torna-se imprescindível a exigência dos caminhos da interdisciplinaridade na assistência à saúde mental nos hospitais gerais. É bom saber que esta exigência não significa a defesa de um saber genérico. Não se trata de substituir as especialidades por generalidades. $O$ que se pleiteia é uma concepção unitária contra uma concepção fragmentada, o que repercutirá de igual modo nas concepções da reforma psiquiátrica.

Chegamos ao século XXI com uma realidade profundamente desumana em todo mundo. Neste contexto, é relevante tratarmos a questão da saúde mental como saúde pública comprometida com o processo de consolidação da democracia, cujo princípio fundamental é a garantia dos Direitos Humanos.

A realidade das pesquisas em todo o país, no que concerne ao portador de transtorno mental, é o retrato fiel de uma sociedade desigual que 
enfrenta a insuficiência do Estado. As estratégias traçadas pelas políticas públicas em saúde mental necessitam, para a sua efetividade, de um possivel despertar - como um violento abrir de janelas - de um amor latente pelo ser humano, pela justiça, ainda não submetidos às regras impostas pelo constituinte. Necessitam, pois, de um amor e de um sonho capazes de compor uma sociedade mais justa e solidária.

\section{REFERÊNCIAS}

ANIYAR DE CASTRO, L. Criminologia da reação social. Rio de Janeiro: Forense, 1983.

ARAÚJO, H. V.; LIMA M. D. C.; MEDEIROS, J. G. M. Expectativas do corpo médico de um hospital geral universitário frente à implantação de uma Unidade Psiquiátrica. Revista Associação Brasileira de Psiquiatria, São Paulo, v. 7, n. 24, p. 32-38, [s.d.].

A REFORMA psiquiátrica. Rio de Janeiro: Ed. Fiocruz 2002.

BASAGLIA, F. A Instituição negada. Rio de Janeiro: Ed. Graal, 1985.

A psiquiatria alternativa - contra o pessimismo da razão o otimismo da prática. São Paulo: Ed. Brasil Debates, 1979.

BASTOS, Celso Ribeiro. Reforma da Constituição. Revista Jurídica Consulex, Brasília, ano 4, v. 1, p. 47, 2000.

BOCKOVEN, J. S. Moral treatment in american psychiatry. Journal of Nervous and Mental Disease, v. 124, p. 167-194, 1956.

BOTEGA, N. Censo Nacional de Unidades de Psiquiatria em Hospitais Gerais II: internações psiquiátricas em enfermarias de clínica médica. Revista ABP-APAL v. 19, p. 87-90, 1997.

BOTEGA N., DALGALARRONDO P. Saúde mental no Hospital Geral. Espaço para o psíquico. São Paulo: Hucitec, 1993.

BOTEGA, N.; SCHECHTMAN, A. Censo Nacional de Unidades de Psiquiatria em Hospitais Gerais I: situação atual e tendências. Revista ABP-APAL, v. 19, p. 79-86, 1997.

BRASIL, M. A. A unidade psiquiátrica em hospital geral. 1982 Dissertação (mestrado) - Instituto de Psiquiatria da Universidade Federal do Rio de Janeiro, Rio de Janeiro, 1982.

CASTEL, R. A ordem psiquiátrica: a idade de ouro do alienismo. Rio de Janeiro: Ed. Graal, 1978.

COMPARATO, Fábio Konder. O Judiciário e os direitos sociais: notas para uma avaliação da justiça brasileira", Brasília, 1994, Seleções Jurídicas-ADV. 
. Fundamentos dos direitos humanos. Revista Jurídica Consulex, Brasilia ano 4, v. 1, p. 48, 2000.

FOUCAULT, M. O nascimento da clínica. Rio de Janeiro: Ed. Forense Universitária, 1977.

leiro, 1975.

Doença mental e psicologia. Rio de Janeiro: Ed. Tempo BrasiHistória da loucura na idade clássica. São Paulo: Ed. Perspectiva, 1978.

Microfisica do poder. Rio de Janeiro: Edições Graal, 2000.

GALENDER, G. A unidade psiquiátrica do Hospital São Paulo. Boletim de Psiquiatria, São Paulo, v. 18, p. 61-63, 1985.

GOFFMAN, E. Manicômios, prisões e conventos. São Paulo: Ed. Perspectiva, 1961.

MINISTÉRIO DA SAÚDE: 2003. Legislação: saúde mental.

MINISTÉRIO PÚBLICO DO DISTRITO FEDERAL E TERRITÓRIOS. 2004. Projeto de saúde mental e Relatórios da Promotoria de Defesa da Saúde PROSUS.

PITTA \& DALLARI, S. G. A cidadania dos doentes mentais no sistema de saúde no Brasil. Saúde em Debate. Revista do Centro Brasileiro de Estudos de Saúde. n. 36, out. 1992.

PITTA, A. Reabilitação psicossocial no Brasil. São Paulo: Hucitec, 1996.

A reintegração do paciente na comunidade. Boletim de Psiquiatria, São Paulo, v. 19, p. 35-36, 1986.

SHIRAKAWA, I.; LEVY JR., M. Experiência da unidade psiquiátrica no Hospital São Paulo. Boletim de Psiquiatria, São Paulo, v. 16, p. 105-108, 1983.

SUCAR, I. Z.; REIS, C. M. e PITTA, J. C. N. O trabalho com famílias de pacientes atendidas na unidade psiquiátrica do Hospital São Paulo da Escola Paulista de Medicina. Boletim de Psiquiatria, São Paulo, v. 20, n. 1/2, p. 23-25, 1987. SZWARC, Wilma Szarf. A Unidade Psiquiátrica do Hospital São Paulo: relato de uma experiência. 1995 Dissertação (Mestrado) Universidade Federal de São Paulo, Escola Paulista de Medicina, 1995. 